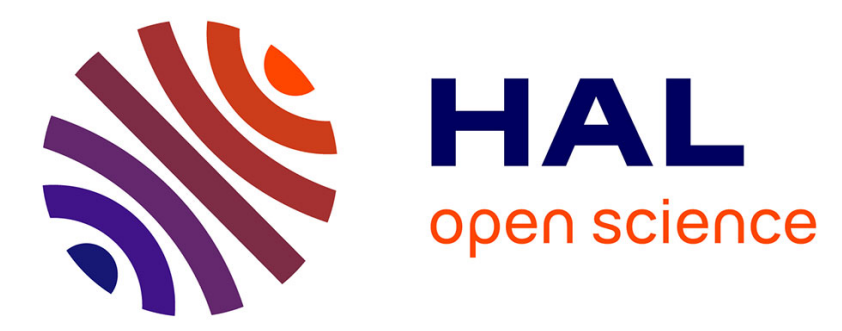

\title{
Variations on the Honeycomb Topology: From Triangular- and Square-Grooved Networks to Tubular Assemblies in Uranyl Tricarballylate Complexes
}

Pierre Thuéry, Jack Harrowfield

\section{To cite this version:}

Pierre Thuéry, Jack Harrowfield. Variations on the Honeycomb Topology: From Triangular- and Square-Grooved Networks to Tubular Assemblies in Uranyl Tricarballylate Complexes. Crystal Growth \& Design, 2017, 17, pp.963-966. 10.1021/acs.cgd.7b00126 . cea-01475689

HAL Id: cea-01475689

https://hal-cea.archives-ouvertes.fr/cea-01475689

Submitted on 24 Feb 2017

HAL is a multi-disciplinary open access archive for the deposit and dissemination of scientific research documents, whether they are published or not. The documents may come from teaching and research institutions in France or abroad, or from public or private research centers.
L'archive ouverte pluridisciplinaire HAL, est destinée au dépôt et à la diffusion de documents scientifiques de niveau recherche, publiés ou non, émanant des établissements d'enseignement et de recherche français ou étrangers, des laboratoires publics ou privés.

\section{(c)(1)}

Distributed under a Creative Commons Attribution| 4.0 International License 


\title{
Variations on the Honeycomb Topology: from Triangular- and Square-Grooved Networks to Tubular Assemblies in Uranyl Tricarballylate Complexes
}

\author{
Pierre Thuéry*,† and Jack Harrowfield* \\ †NIMBE, CEA, CNRS, Université Paris-Saclay, CEA Saclay, 91191 Gif-sur-Yvette, France \\ †ISIS, Université de Strasbourg, 8 allée Gaspard Monge, 67083 Strasbourg, France
}

Supporting Information Placeholder

\begin{abstract}
Depending on the counterion, uranyl tricarballylate, $\mathrm{UO}_{2}(\mathrm{tca})^{-}$, is shown to crystallize either as two-dimensional nets or as one-dimensional tubules, all with honeycomb topology and united into higher dimensional assemblies when additional metal cations $\left(\mathrm{Ag}^{\mathrm{I}}, \mathrm{Pb}^{\mathrm{II}}\right)$ are present. A regular geometric progression involving ligands reorientation is apparent in the series, with triangular furrows in $\left[\mathrm{H}_{2} \mathrm{NMe}_{2}\right]\left[\mathrm{UO}_{2}\right.$ (tca) $] \cdot \mathrm{H}_{2} \mathrm{O}$ (1) followed by deepening square grooves in $\left[\mathrm{UO}_{2} \mathrm{Ag}(\mathrm{tca})\left(\mathrm{H}_{2} \mathrm{O}\right)\right] \cdot 0.5 \mathrm{H}_{2} \mathrm{O}(\mathbf{2})$ and full closure of square tubules in $\left[\mathrm{NH}_{4}\right]\left[\left(\mathrm{UO}_{2}\right)_{2} \mathrm{~Pb}(\mathrm{tca})_{2}\left(\mathrm{NO}_{3}\right)\right.$ (bipy)].
\end{abstract}

Since the first reports of uranyl-based nanotubular structures in phosphonate complexes by Clearfield et al. more than 20 years ago, ${ }^{1-5}$ the number of such species has steadily increased and, although they are still uncommon, as expected for this linear cation, they appear to be accessible from a variety of ligand classes. While most examples are still found among phosphonates ${ }^{1-8}$ remarkable inorganic tubular arrangements have been found in uranyl selenates, ${ }^{9-}$ ${ }^{11}$ and polycarboxylates, prevalent in the design of uranylorganic coordination polymers, ${ }^{12-14}$ have also provided several cases in recent years. ${ }^{15-19}$ Among the latter, phthalate (1,2-benzenedicarboxylate) gives tubular species through connection of hexanuclear rings ${ }^{16}$ (an analogous complex with neptunyl has also been reported $\left.{ }^{20}\right)$; Kemp's tricarboxylate (cis,cis-1,3,5-trimethylcyclohexane-1,3,5tricarboxylate) yields uranyl-nickel(II) heterometallic tubules or uranyl octanuclear cages depending on whether $\mathrm{Ni}^{\mathrm{II}}$-bound 2,2'-bipyridine molecules are present or not, ${ }^{17}$ and the related cis,cis-1,3,5-cyclohexanetricarboxylate gives either two-dimensional (2D) honeycomb networks or a tubular assembly retaining the same topology, depending on the choice of counterions..$^{18}$ Apart from coordination bonds, supramolecular interactions may also be summoned to create such species, and tubular channels are formed through hydrogen bonding of corrugated hexanuclear uranyliminodiacetate rings. ${ }^{19}$ Due to its curved shape, tricarballylic acid (1,2,3-propanetricarboxylic acid, $\mathrm{H}_{3}$ tca) is of potential interest to generate uranyl-containing polymers with curved architectures, but the only complex reported so far, $\left[\mathrm{UO}_{2} \mathrm{Na}(\mathrm{tca})\left(\mathrm{H}_{2} \mathrm{O}\right)_{4}\right]$, crystallizes as a $2 \mathrm{D}$ network with honeycomb topology. ${ }^{21}$ By varying the experimental conditions, we have now obtained three novel uranyl tricarballylate complexes, two of which are heterometallic and include $\mathrm{Ag}^{\mathrm{I}}$ or $\mathrm{Pb}^{\mathrm{II}}$ cations, that were synthesized solvohydrothermally and have been characterized by their crystal structure. ${ }^{22}$ One of these complexes provides a new example of a tubular arrangement, deriving from a regular progression of geometric features in the series.

The asymmetric unit in $\left[\mathrm{H}_{2} \mathrm{NMe}_{2}\right]\left[\mathrm{UO}_{2}(\mathrm{tca})\right] \cdot \mathrm{H}_{2} \mathrm{O}$ (1) contains a unique uranyl ion located on a mirror plane and chelated by three carboxylate groups from three tca ${ }^{3-}$ ligands (Fig. 1). The $\mathrm{U}-\mathrm{O}$ (oxo) bond lengths of 1.757(8) and $1.758(7) \AA$, and the U-O(carboxylate) bond lengths of 2.462(5)-2.468(5) $\AA$ are unexceptional. Both metal and ligand are threefold nodes and they generate a $2 \mathrm{D}$ network parallel to $\left(\begin{array}{lll}1 & 0 & 0\end{array}\right)$, with the point (Schläfli) symbol $\left\{6^{3}\right\}$ (honeycomb topology). This assembly is similar to that in the previously reported complex $\left[\mathrm{UO}_{2} \mathrm{Na}(\mathrm{tca})\left(\mathrm{H}_{2} \mathrm{O}\right)_{4}\right](\mathbf{4}),{ }^{21}$ both displaying triangular grooves. In both cases, grooves from adjacent layers are facing one another so as to form channels that are occupied by carboxylate- and oxo-bound $\mathrm{Na}\left(\mathrm{H}_{2} \mathrm{O}\right)_{4}{ }^{+}$cations in complex $\mathbf{4}$, and by disordered, hydrogen bonded $\mathrm{H}_{2} \mathrm{NMe}_{2}{ }^{+}$cations in $\mathbf{1}$, the latter cations being formed in situ from DMF hydrolysis; the Kitaigorodski packing index (KPI) for $\mathbf{1}$ is $\sim 0.69$. This peculiar geometry of the sheets results from the 1,3carboxylate groups being in a common plane approximately perpendicular to that of the 2-carboxylate group [dihedral angle $\theta_{\mathrm{ca}}=86.8(8)^{\circ}$ ], the equatorial planes of the uranyl ions bound to these groups retaining approximately the same geometrical relationship.

The asymmetric unit in $\left[\mathrm{UO}_{2} \mathrm{Ag}(\mathrm{tca})\left(\mathrm{H}_{2} \mathrm{O}\right)\right] \cdot 0.5 \mathrm{H}_{2} \mathrm{O}$ (2) contains two uranyl and two silver(I) cations, and two tca ${ }^{3-}$ ligands (Figs. 2 and S1, Supporting Information). Both uranyl cations are in similar environments with three chelating carboxylate groups from three ligands $[\mathrm{U}-\mathrm{O}$ bond 

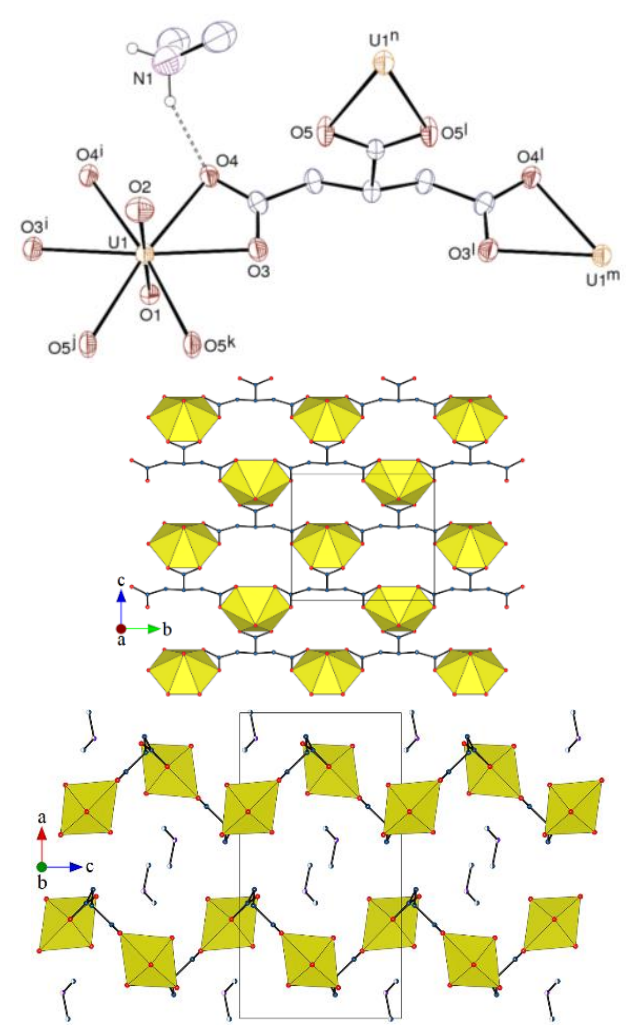

Figure 1. Top: View of compound 1. Displacement ellipsoids are drawn at the $30 \%$ probability level. The solvent molecule and carbon-bound hydrogen atoms are omitted, and only one position of the disordered counterion is shown. The hydrogen bond is shown as a dashed line. Symmetry codes: $\mathrm{i}=x, 3 / 2-y, z ; \mathrm{j}=1 / 2-x, y+1 / 2, z-1 / 2 ; \mathrm{k}=1 / 2-x, 1$ $-y, z-1 / 2 ; 1=x, 1 / 2-y, z ; \mathrm{m}=x, y-1, z ; \mathrm{n}=1 / 2-x, 1-y, z+1 / 2$. Middle: View of the 2D assembly. Bottom: View of the packing. Uranium coordination polyhedra are colored yellow and solvent molecules and hydrogen atoms are omitted in the last two views.

lengths of 2.418(8)-2.499(8) $\AA$, average 2.46(2) $\AA$ ]. In contrast, the two silver(I) cations are in different environments. $\mathrm{Ag} 1$ is chelated by atoms $\mathrm{O} 14$ and $\mathrm{O} 15$ from two carboxylate groups of the same ligand [bond lengths of $2.516(10)$ and $2.455(9) \AA$, respectively] and bound to a water molecule (O17) at 2.228(10) $\AA$; three longer contacts with two carboxylate oxygen atoms from two more ligands [2.733(11) and 2.895(9) $\AA$ ] and with the oxo atom $\mathrm{O}^{1}$ $[2.739(9) \AA]$ make for a very irregular environment, with the oxo atom in axial position with respect to the average plane defined by the five other donors. Atom $\mathrm{Ag} 2$ is bound to the two carboxylate oxygen atoms $\mathrm{O} 7$ and $\mathrm{O} 11^{\mathrm{j}}$, at 2.518(8) and 2.327(8) $\AA$, respectively, and to a bridging water molecule (O18) and its image by inversion [2.414(10) and 2.493(9) $\AA]$; it is also involved in two longer contacts with the carboxylate atom $\mathrm{O} 10$ at $2.700(9) \AA$, and the oxo atom $\mathrm{O} 1^{\mathrm{m}}$ at $2.779(10) \AA$. The environment of $\mathrm{Ag} 2$ has also an irregular geometry, but it can be viewed as a very distorted octahedron. The oxo atom $\mathrm{O} 1$ is thus involved in a bifurcated bond with the two silver cations, which is however weak since no significant lengthening of the $\mathrm{U} 1-\mathrm{O} 1$ bond is measured [1.792(8) $\AA$, versus $1.780(8) \AA$ for $\mathrm{U} 1-\mathrm{O} 2$; the bond lengths for $\mathrm{U} 2$ are $1.766(8)$ and $1.770(8) \AA]$. The dihedral angles $\theta_{\text {ca }}$ are $85.7(12)$ and $78.5(11)^{\circ}$ for the two independent anions, the latter significantly reduced with respect to the value in $\mathbf{1}$. Each tca ${ }^{3-}$ ligand is bound to three
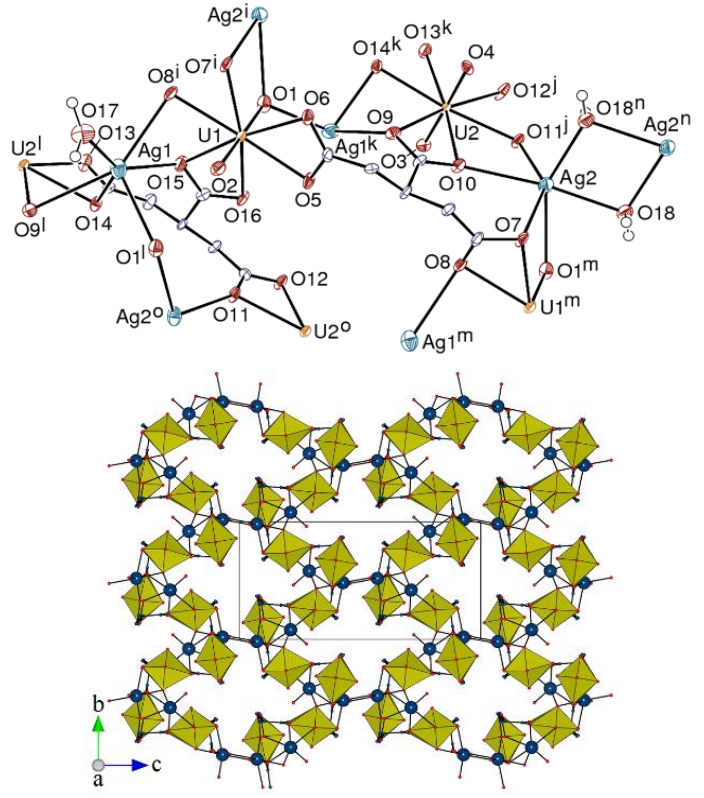

Figure 2. Top: View of compound 2. Displacement ellipsoids are drawn at the $50 \%$ probability level. The solvent molecule and carbon-bound hydrogen atoms are omitted. Symmetry codes: $\mathrm{i}=x-1, y, z ; \mathrm{j}=1-x, y+$ $1 / 2,1 / 2-z ; \mathrm{k}=-x, y+1 / 2,1 / 2-z ; 1=-x, y-1 / 2,1 / 2-z ; \mathrm{m}=x+1, y, z ;$ $\mathrm{n}=2-x, 1-y, 1-z ; \mathrm{o}=1-x, y-1 / 2,1 / 2-z$. Bottom: View of the $3 \mathrm{D}$ framework with the uranium coordination polyhedra colored yellow and silver atoms shown as blue spheres; the $2 \mathrm{D}$ honeycomb subunits are viewed edge-on; solvent molecules and hydrogen atoms are omitted.

uranyl ions and to either two or three $\mathrm{Ag}^{\mathrm{I}}$ ions, the coordination modes of the carboxylate groups being $\kappa^{2} O, O^{\prime}$, $\mu_{2}-\kappa^{1} O: \kappa^{2} O, O^{\prime}$ or $\mu_{3}-\kappa^{1} O: \kappa^{2} O, O^{\prime}: \kappa^{1} O^{\prime}$. If only the uranyl cations and $\mathrm{tca}^{3-}$ ligands are considered, a $2 \mathrm{D}$ network parallel to $\left(\begin{array}{lll}0 & 0 & 1\end{array}\right)$ is generated, with the same honeycomb topology as that in $\mathbf{1}$ and $\mathbf{4}$; however, instead of displaying a triangular furrowing, this assembly is deeply corrugated and the grooves are square-shaped, a difference apparent in the nodal representations shown in Fig. 3. The difference between the geometries observed in $\mathbf{1 / 4}$ and $\mathbf{3}$ arises from the different number of ligand units defining each groove, two in the former case and three in the latter. $\mathrm{Ag} 1$ and its symmetry equivalents are located inside these layers and do not lead to a dimensionality increase, while $\mathrm{Ag} 2$ and its equivalents are located at the periphery of the sheets and, through formation of doubly water-bridged silver(I) dimers, unite the 2D subunits into a 3D framework. Roughly elliptical channels run along the $a$ axis, due to the grooves facing each other as in $\mathbf{1}$, that do not exceed $\sim 3 \AA$ in their narrowest parts and are thus too small for any practical use. The framework is compact, as shown by its KPI of 0.77 . The coordinated and free water molecules form an intricate network of rather weak simple, bifurcate or even trifurcate hydrogen bonds, the acceptors being uranyl oxo, carboxylate

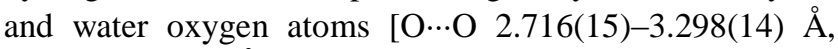
$\left.\mathrm{H} \cdots \mathrm{O} 2.14-2.52 \AA, \mathrm{O}-\mathrm{H} \cdots \mathrm{O} 108-164^{\circ}\right]$.

Replacement of $\mathrm{Ag}^{\mathrm{I}}$ by the divalent $\mathrm{Pb}^{\mathrm{II}}$ results in a different stoichiometry in the complex $\left[\mathrm{NH}_{4}\right]\left[\left(\mathrm{UO}_{2}\right)_{2} \mathrm{~Pb}(\mathrm{tca})_{2}\left(\mathrm{NO}_{3}\right)\right.$ (bipy) $]$ (3) (bipy = 2,2'bipyridine), in which the ammonium cations appear to have been generated in situ from acetonitrile hydrolysis possibly catalyzed by $\mathrm{U}^{\mathrm{VI}}$, a similar phenomenon having previously 


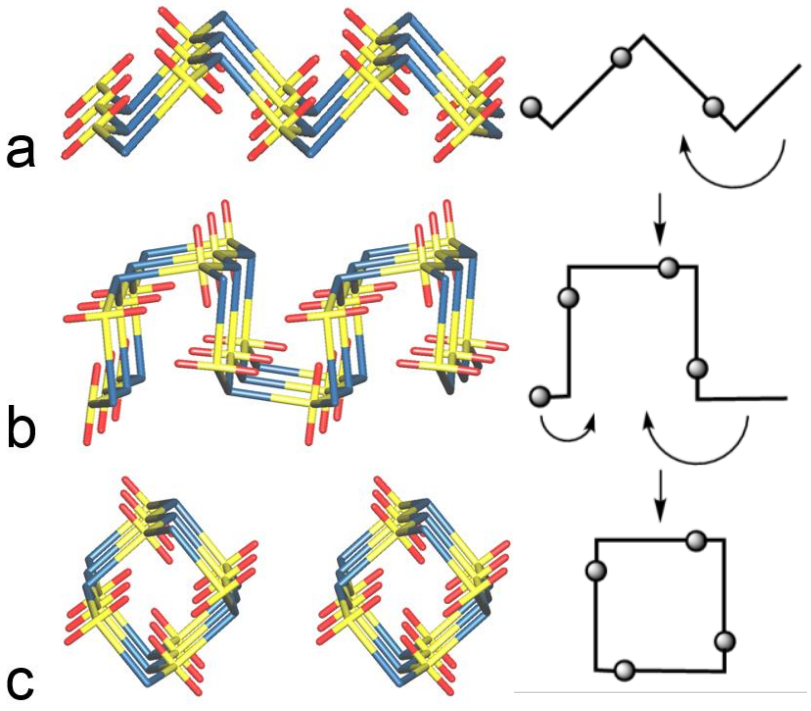

Figure 3. Nodal representation of the triangular-grooved network in $\mathbf{1 / 4}$ (a), the square-grooved network in $\mathbf{2}$ (b), and the tubular chains in $\mathbf{3}$ (c), and schematic representation of the transformation. Yellow: uranium, red: oxygen, blue: tricarballylate ligand.

been encountered during the synthesis of a uranyl pimelate complex. ${ }^{23}$ The two crystallographically independent uranyl ions are both chelated by three carboxylate groups, with unexceptional U-O(oxo) [1.758(4)-1.779(5) $\AA$, average

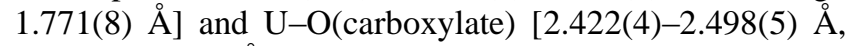
average 2.46(2) $\AA$ ] bond lengths (Figs. 4 and S2, Supporting Information). The unique lead(II) cation is chelated by the bipy molecule $[\mathrm{Pb}-\mathrm{N}$ bond lengths $2.422(6)$ and 2.452(5) $\AA]$ and is bound to the carboxylate atom O6 at 2.722(4) $\AA$ and three oxygen atoms pertaining to two nitrate anions, two of them (O17 and O18) being chelating [2.515(5) and 2.723(6) $\AA]$ and the third $\left(\mathrm{O} 19^{1}\right)$ monodentate [2.847(6) $\AA$ ]. The nitrate ion is thus bound in a $\mu_{2}-\kappa^{1} O: \kappa^{2} O^{\prime}, O^{\prime \prime}$ coordination mode. A longer contact exists between $\mathrm{Pb} 1$ and $\mathrm{O} 14^{\mathrm{k}}$, at 3.193(4) $\AA$. Depending on whether this last contact is considered as a true bond or not, the coordination number is six or seven, but the environment is in both cases more hemithan holodirected. ${ }^{24}$ The tca ${ }^{3-}$ ligand is here also in its rightangled shape, with dihedral angles $\theta_{\text {ca }}$ of $87.8(5)$ and 88.2(7) $)^{\circ}$, but, instead of generating a $2 \mathrm{D}$ lattice, the $\mathrm{UO}_{2}(\mathrm{tca})^{-}$assembly is folded so as to create a tubular 1D polymer directed along the $a$ axis, while retaining the $\left\{6^{3}\right\}$ topology. The cross-section of the tubules is square, with an edge length of $\sim 6 \AA$, the uranium atoms on the four edges being offset along the $a$ axis, so that sufficient inner space is available for inclusion of the $\mathrm{NH}_{4}{ }^{+}$counterions. The latter are hydrogen bonded to two uranyl oxo and two carboxylate groups from opposite sides of the cavity [N...O 2.971(8)3.031(9) $\AA, \mathrm{H} \cdots \mathrm{O} 2.16-2.35 \AA, \mathrm{N}-\mathrm{H} \cdots \mathrm{O} 134-175^{\circ}$ ], so that it may be surmised that they exert a structure-directing role. The tubules are further assembled into a $2 \mathrm{D}$ lattice parallel to $\left(\begin{array}{lll}0 & 1 & 0\end{array}\right)$ by centrosymmetric nitrate-bridged $\mathrm{Pb}^{\mathrm{II}}$ dimers (KPI 0.74), an arrangement reminiscent of the bridging of uranyl phosphonate tubules by $\mathrm{Cu}^{\mathrm{II}}$ cations. ${ }^{8}$

A regular geometric progression is thus apparent in this series, from triangular and square grooves defined by two and three ligands, respectively, to tubular shapes lined by four ligands. From a purely geometric point of view, this
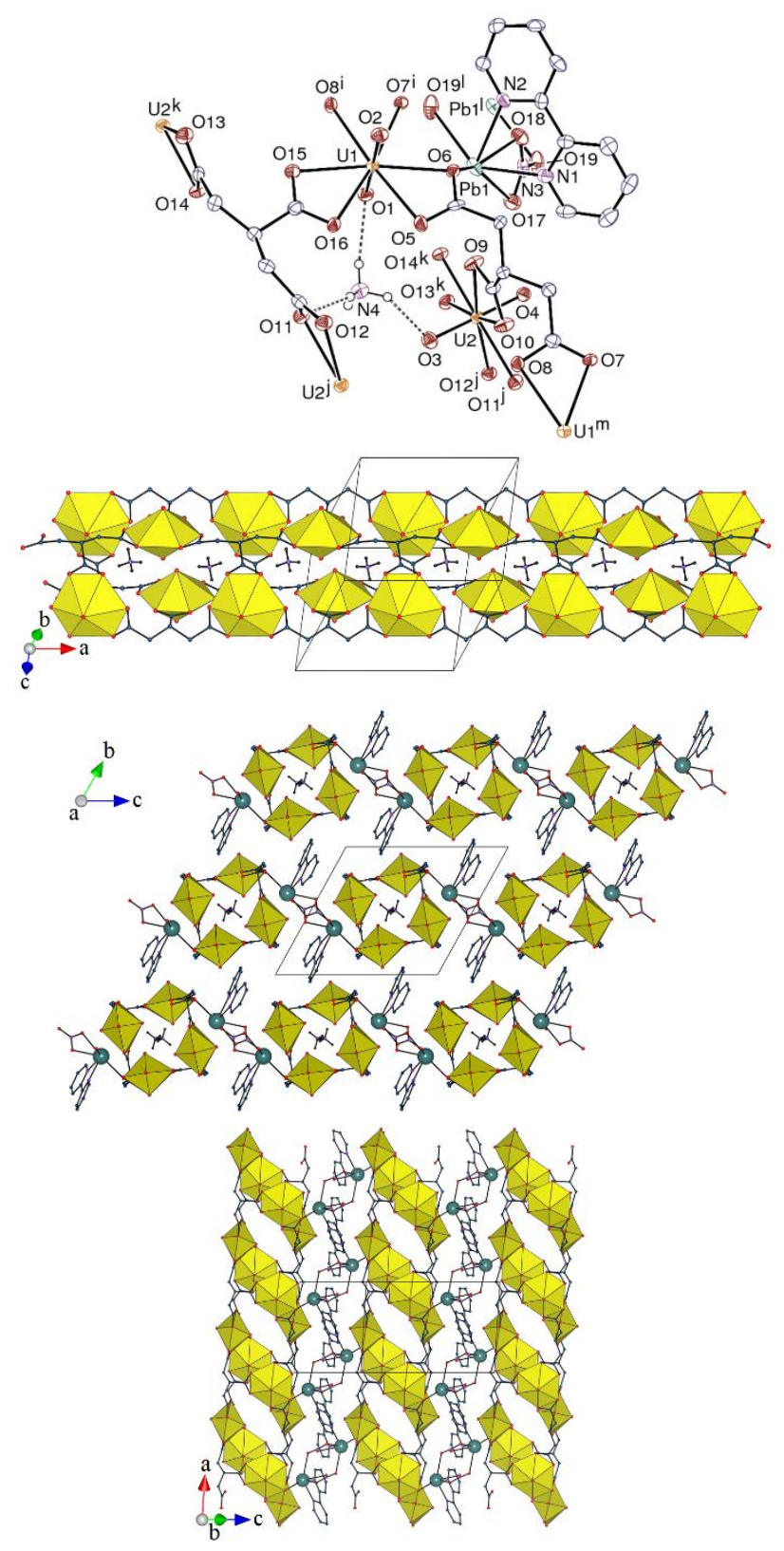

Figure 4. Top: View of compound 3. Displacement ellipsoids are drawn at the $40 \%$ probability level. Carbon-bound hydrogen atoms are omitted and hydrogen bonds are shown as dashed lines. Symmetry codes: $\mathrm{i}=x+1, y, z$; $\mathrm{j}=1-x, 1-y, 1-z ; \mathrm{k}=2-x, 1-y, 1-z ; 1=2-x, 1-y, 2-z ; \mathrm{m}=x-1$, $y, z$. Middle: View of one tubular subunit. Bottom: Two views of the packing parallel and perpendicular to the tubules axis, with the uranium coordination polyhedra colored yellow, lead atoms shown as green spheres, and hydrogen atoms omitted, except for those of the $\mathrm{NH}_{4}{ }^{+}$counterions.

transformation involves reorientation of otherwise conformationally almost invariant ligands so that the direction of connection changes by $180^{\circ}$, the topology being unmodified (Fig. 3). A similar conversion of an undulated honeycomb 2D network into a tubular assembly has previously been encountered in uranyl ion complexes with cis, ,is-1,3,5-cyclohexanetricarboxylate, ${ }^{18}$ but no intermediate step was found in this case. Of course, the mechanism of formation of the tubules in $\mathbf{3}$ is unknown and, although formation of nanotubes through folding of the corresponding sheets is a known mechanism, ${ }^{9,10}$ it most probably does not involve $2 \mathrm{D}$ intermediates analogous to 
those in $\mathbf{1} / \mathbf{4}$ and $\mathbf{2}$ since ligand reorientation would require the breaking of bonds. The nature of the counterions obviously plays a key-role in the choice of a particular outcome. In particular, the ammonium counterions may be essential in organizing the ligands, during polymer growth, in the best position for hydrogen bonding, thus favoring the formation of a closed assembly encircling the $\mathrm{NH}_{4}{ }^{+}$ divergent, fourfold hydrogen bond donor. The aptitude of honeycomb nets to accommodate folding is particularly evident in carbon nanotubes..$^{25} \mathrm{With}$ respect to those, the size of the tubular species in $\mathbf{3}$ is limited by the fact that only four metal/ligand units are sufficient to ensure closure, which is related to one uranium node being markedly displaced from the mean plane of the five other nodes of the hexagonal honeycomb ring, thus giving the latter a pronounced angular shape well suited to define a square cross-section. Larger tubules are obtained when six uranyl/ligand units subtend the tube perimeter, a situation common with other polycarboxylates ${ }^{15-19}$ as well as phosphonates, ${ }^{1}$ although narrower tubes with four-membered cross-sections were also found in the latter case. ${ }^{2,4}$

The emission spectra of complexes $\mathbf{1}$ and $\mathbf{3}$ in the solid state were measured at room temperature under excitation at $420 \mathrm{~nm}$ (Figure S3, Supporting Information; no sufficient amount of pure 2 could be obtained). The usual vibronic fine structure $^{26-28}$ is observed in both cases, with the maxima positions being redshifted by $3 \mathrm{~nm}$ in complex 3 with respect to those in 1. These positions $(463,480,500,522$ and 545 $\mathrm{nm}$ in 1) are in good agreement with those for other complexes with uranyl ions chelated by three carboxylate groups. ${ }^{18,23,29}$

In summary, it appears that, depending on the choice of counterion, uranyl tricarballylate crystallizes as 2D networks with variable degrees and shapes of corrugation, or as a tubular species in which closure is fully achieved. All these forms having a common honeycomb topology, a frequently encountered geometry in uranyl coordination polymers, this points to the possibility of generating other tubular structures, with a diameter depending on the ligand curvature and geometrical flexibility.

\section{ASSOCIATED CONTENT}

\section{Accession Codes}

CCDC 1529441-1529443 contains the supplementary crystallographic data for this paper. These data can be obtained free of charge via www.ccdc.cam.ac.uk/data_request/cif, or by emailing data_request@ccdc.cam.ac.uk, or by contacting The Cambridge Crystallographic Data Centre, 12, Union Road, Cambridge CB2 1EZ, UK; fax: +44 1223336033.

\section{Supporting Information}

The Supporting Information is available free of charge on the ACS Publications website at DOI.. Experimental details, additional figures, emission and excitation spectra of compounds $\mathbf{1}$ and $\mathbf{3}$. (PDF)

\section{AUTHOR INFORMATION}

Corresponding Authors
*E-mail: pierre.thuery@cea.fr (P. T.)

\section{Notes}

The authors declare no competing financial interest.

\section{REFERENCES}

1. Poojary, D. M.; Grohol, D.; Clearfield, A. Angew. Chem., Int. Ed. 1995, 34, 1508-1510.

2. Poojary, D. M.; Cabeza, A.; Aranda, M. A. G.; Bruque, S.; Clearfield, A. Inorg. Chem. 1996, 35, 1468-1473.

3. Grohol, D.; Clearfield, A. J. Am. Chem. Soc. 1997, 119, 9301-9302.

4. Aranda, M. A. G.; Cabeza, A.; Bruque, S.; Poojary, D. M.; Clearfield, A. Inorg. Chem. 1998, 37, 1827-1832.

5. Gagnon, K. J.; Perry, H. P.; Clearfield, A. Chem. Rev. 2012, 112, 1034 1054.

6. Adelani, P. O.; Albrecht-Schmitt, T. E. Angew. Chem., Int. Ed. 2010, 49, 8909-8911.

7. Adelani, P. O.; Albrecht-Schmitt, T. E. Inorg. Chem. 2011, 50, 12184 12191.

8. Adelani, P. O.; Cook, N. D.; Babo, J. M.; Burns, P. C. Inorg. Chem. 2014, 53, 4169-4176.

9. Krivovichev, S. V.; Kahlenberg, V.; Tananaev, I. G.; Kaindl, R.; Mersdorf, E.; Myasoedov, B. F. J. Am. Chem. Soc. 2005, 127, 10721073.

10. Krivovichev, S. V.; Kahlenberg, V.; Kaindl, R.; Mersdorf, E.; Tananaev, I. G.; Myasoedov, B. F. J. Angew. Chem. Int. Ed. 2005, 44, 1134-1136.

11. Krivovichev, S. V. Eur. J. Inorg. Chem. 2010, 2594-2603.

12. Andrews, M. B.; Cahill, C. L. Chem. Rev. 2013, 113, 1121-1136.

13. Loiseau, T.; Mihalcea, I.; Henry, N.; Volkringer, C. Coord. Chem. Rev. 2014, 266-267, 69-109.

14. Su, J.; Chen, J. S. Struct. Bond. 2015, 163, 265-296.

15. Thuéry, P. Inorg. Chem. Commun. 2008, 11, 616-620.

16. Mihalcea, I.; Henry, N.; Loiseau, T. Cryst. Growth Des. 2011, 11, 1940-1947.

17. Thuéry, P. Cryst. Growth Des. 2014, 14, 901-904.

18. Thuéry, P.; Harrowfield, J. Cryst. Growth Des. 2014, 14, 4214-4225.

19. Unruh, D. K.; Gojdas, K.; Libo, A.; Forbes, T. Z. J. Am. Chem. Soc. 2013, 135, 7398-7401.

20. Grigoriev, M. S.; Antipin, M. Y.; Krot, N. N.; Bessonov, A. A. Radiochim. Acta 2004, 92, 405-409.

21. Thuéry, P. Chem. Commun. 2006, 853-855.

22. Crystal data for 1: $\mathrm{C}_{8} \mathrm{H}_{15} \mathrm{NO}_{9} \mathrm{U}, M=507.24$, orthorhombic, space group Pnma, $a=16.5103(11), b=9.9630(5), c=8.7565(6) \AA, \quad V=$ $1440.38(16) \AA^{3}, Z=4$. Refinement of 113 parameters on 1436 independent reflections out of 53571 measured reflections $\left(R_{\text {int }}=\right.$ $0.019)$ led to $\mathrm{R} 1=0.036, \mathrm{wR} 2=0.095, S=1.144, \Delta \rho_{\min }=-1.00, \Delta \rho_{\max }$ $=2.44 \mathrm{e}^{-3}$. Crystal data for $2: \mathrm{C}_{6} \mathrm{H}_{8} \mathrm{AgO}_{9.5} \mathrm{U}, M=578.03$, monoclinic, space group $P 2_{1} / c, a=10.0314(2), b=10.2446(3), c=21.0228(6) \AA, \beta$ $=90.267(2)^{\circ}, V=2160.44(10) \AA^{3}, Z=8$. Refinement of 317 parameters on 4107 independent reflections out of 121896 measured reflections $\left(R_{\text {int }}=0.031\right)$ led to $\mathrm{R} 1=0.037, \mathrm{wR} 2=0.110, S=1.136, \Delta \rho_{\min }=-$ $4.28, \Delta \rho_{\max }=1.70 \mathrm{e}^{-3}$. Crystal data for 3: $\mathrm{C}_{22} \mathrm{H}_{22} \mathrm{~N}_{4} \mathrm{O}_{19} \mathrm{PbU}_{2}, M=$ 1329.68, triclinic, space group $P \overline{1}, a=10.0187(5), b=13.1772(10), c$ $=13.7467(10) \AA, \alpha=62.229(3), \beta=88.065(4), \gamma=69.737(4)^{\circ}, V=$ $1488.50(19) \AA^{3}, Z=2$. Refinement of 433 parameters on 5641 independent reflections out of 68981 measured reflections $\left(R_{\mathrm{int}}=\right.$ 0.080 ) led to $\mathrm{R} 1=0.030, \mathrm{wR} 2=0.063, S=1.096, \Delta \rho_{\min }=-1.69, \Delta \rho_{\max }$ $=1.32$ e $\AA^{-3}$.

23. Thuéry, P.; Rivière, E.; Harrowfield, J. Cryst. Growth Des. 2016, 16, 2826-2835.

24. Shimoni-Livny, L.; Glusker, J. P.; Bock, C. W. Inorg. Chem. 1998, 37, 1853-1867.

25. Iijima, S. Nature 1991, 354, 56-58.

26. Frisch, M.; Cahill, C. L. Dalton Trans. 2006, 4679-4690.

27. Redmond, M. P.; Cornet, S. M.; Woodall, S. D.; Whittaker, D.; Collison, D.; Helliwell, M.; Natrajan, L. S. Dalton Trans. 2011, 40, 3914-3926.

28. Thangavelu, S. G.; Cahill, C. L. Cryst. Growth Des. 2016, 16, 42-50.

29. Thuéry, P.; Harrowfield, J. Inorg. Chem. 2017, 56, 1455-1469. 


\section{Variations on the Honeycomb Topology: from Triangular- and Square- Grooved Networks to Tubular Assemblies in Uranyl Tricarballylate Complexes}

Pierre Thuéry and Jack Harrowfield

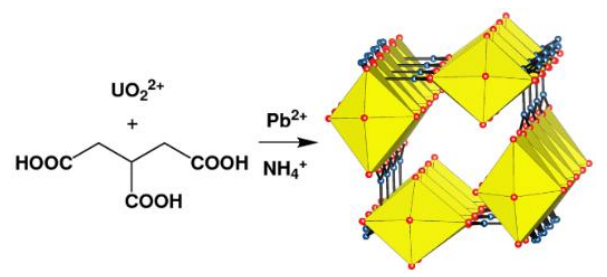

The right-angled curvature of the tricarballylate ligand gives a corrugated shape to the two-dimensional honeycomb assemblies it forms with the uranyl cation. The shape of the furrows can be monitored through the choice of counterions, resulting in triangular or square geometries, and finally closure of the grooves to form tubules with square cross-section. 